\title{
Neutrophil to lymphocyte ratio, not platelet to lymphocyte or lymphocyte to monocyte ratio, is predictive of patient survival after resection of early-stage pancreatic ductal adenocarcinoma
}

David T. Pointer Jr. ', David Roife', Benjamin D. Powers', Gilbert Murimwa², Sameh Elessawy', Zachary J. Thompson ${ }^{3}$, Michael J. Schell ${ }^{3}$, Pamela J. Hodul' ${ }^{1}$, Jose M. Pimiento ${ }^{1}$, Jason B. Fleming ${ }^{1}$ and Mokenge P. Malafa ${ }^{1 *}$

\begin{abstract}
Background: NLR, PLR, and LMR have been associated with pancreatic ductal adenocarcinoma (PDAC) survival. Prognostic value and optimal cutpoints were evaluated to identify underlying significance in surgical PDAC patients.

Methods: NLR, PLR, and LMR preoperative values were available for 277 PDAC patients who underwent resection between 2007 and 2015. OS, RFS, and survival probability estimates were calculated by univariate, multivariable, and Kaplan-Meier analyses. Continuous and dichotomized ratio analysis determined best-fit cutpoints and assessed ratio components to determine primary drivers.

Results: Elevated NLR and PLR and decreased LMR represented 14\%, 50\%, and 50\% of the cohort, respectively. OS $(P=.002)$ and RFS ( $P=.003)$ were significantly decreased in resected PDAC patients with NLR $\geq 5$ compared to those with NLR < 5. Optimal prognostic OS and RFS cutpoints for NLR, PLR, and LMR were 4.8, 192.6, and 1.7, respectively. Lymphocytes alone were the primary prognostic driver of NLR, demonstrating identical survival to NLR.

Conclusions: NLR is a significant predictor of OS and RFS, with lymphocytes alone as its primary driver; we identified optimal cutpoints that may direct future investigation of their prognostic value. This study contributes to the growing evidence of immune system influence on outcomes in early-stage pancreatic cancer.
\end{abstract}

Keywords: Neutrophil lymphocyte ratio, Platelet lymphocyte ratio, Lymphocyte monocyte ratio, Pancreatic cancer, Biomarker

\footnotetext{
*Correspondence: mokenge.malafa@moffitt.org

'Department of Gastrointestinal Oncology, H. Lee Moffitt Cancer Center and Research Institute, 12902 USF Magnolia Dr, Tampa, FL 33612, USA

Full list of author information is available at the end of the article
}

(c) The Author(s). 2020 Open Access This article is licensed under a Creative Commons Attribution 4.0 International License, which permits use, sharing, adaptation, distribution and reproduction in any medium or format, as long as you give appropriate credit to the original author(s) and the source, provide a link to the Creative Commons licence, and indicate if changes were made. The images or other third party material in this article are included in the article's Creative Commons licence, unless indicated otherwise in a credit line to the material. If material is not included in the article's Creative Commons licence and your intended use is not permitted by statutory regulation or exceeds the permitted use, you will need to obtain permission directly from the copyright holder. To view a copy of this licence, visit http://creativecommons.org/licenses/by/4.0/ The Creative Commons Public Domain Dedication waiver (http://creativecommons.org/publicdomain/zero/1.0/) applies to the data made available in this article, unless otherwise stated in a credit line to the data. 


\section{Background}

Pancreatic ductal adenocarcinoma (PDAC) is the third leading cause of cancer-related death in the US, with an estimated 45,750 deaths in 2019 and a 5-year overall survival (OS) rate of 9\% [1]. Among newly diagnosed PDAC patients, only 15 to $20 \%$ present with resectable disease. With resection as the only chance for cure, prognosis is generally poor with reported 5-year OS of 10-30\% after resection [2-6]. AJCC TNM staging is the only widely accepted indicator of prognosis for resectable pancreatic cancer; however its performance in early-stage disease has been questioned [7]. Additionally, controversy regarding initial treatment of early-stage pancreatic cancer persists, yielding no uniform treatment algorithm. Given the wide variation in the biological behavior of PDAC and treatment algorithms for this disease, there is an unmet need for enhanced prognostic biomarkers. Biomarkers derived from easily obtainable laboratory values have shown potential to meet this need and may help to stratify patients with early-stage pancreatic cancer and guide future treatment plans.

Conventionally, survival outcomes among cancer patients have been determined by the disease stage and receipt of treatment. More recently, however, increased attention has been directed toward the role of inflammation and immune response in the tumor microenvironment and their effects on tumor behavior. Quantifying the systemic inflammatory response by C-reactive protein and various nutritional parameters has shown prognostic significance in gastrointestinal, gynecological and thoracic cancers [8]. Additionally, inflammatory indices and immunologic ratios, including ratios comprised of intratumoral or circulating neutrophils, platelets, lymphocytes, and monocyte counts, have been proposed to be prognostic biomarkers for a wide range of malignancies [9-12].

The neutrophil to lymphocyte ratio (NLR), platelet to lymphocyte ratio (PLR), and lymphocyte to monocyte ratio (LMR) are among the many surrogate biomarkers for inflammation that have been associated with outcomes in gastrointestinal cancers. Although these ratios have been reported to have promising prognostic value, few studies have examined the effect of these inflammatory ratios in US surgical cohorts [12-18]. Moreover, many single-institution studies have reported inconsistent prognostic outcomes for these surrogate biomarkers. We previously reported an inverse association between survival and NLR in patients with borderline resectable disease [14]. To expand the scope of our previous analysis, we evaluated the prognostic significance of the NLR, PLR, and LMR in a cohort of patients with resected PDAC who were treated at a high-volume cancer center. Furthermore, we aimed to establish optimal NLR, PLR, and LMR cutpoints for determining OS and recurrence- free survival (RFS) and define the primary factor driving the prognostic value of these ratios for survival outcomes. We hypothesized that preoperatively increased NLR and PLR and decreased LMR were associated with worse OS in patients with resectable PDAC.

\section{Methods}

A retrospective review was conducted using our institutional prospective pancreatic cancer database, as part of our ongoing outcome-based study. The study was approved by our Institutional Review Board (MCC\#16446), and patient consent was unable to be obtained as this study was conducted retrospectively on de-identified data, posing less than minimal risk. Patients diagnosed with PDAC who underwent curative-intent resection for the treatment of their disease were identified. Resectable and borderline resectable PDAC patients were defined and included on the basis of the NCCN guidelines applied at the time of diagnosis. Pancreatic resection included open or minimally invasive pancreaticoduodenectomy, total pancreatectomy, and distal pancreatectomy performed at our institution.

Patient characteristics were summarized using descriptive statistics, including median and range for continuous measures and proportions and frequencies for categorical measures. Kaplan-Meier plots were made to determine OS and RFS for the NLR, PLR, and LMR. Survival probability estimates were calculated using the Kaplan-Meier method. Univariate and multivariable Cox proportional-hazard models for OS and RFS were run for each ratio as continuous predictors and dichotomized forms. The NLR, PLR, and LMR were calculated by dividing the absolute neutrophil count by the lymphocyte count, the platelet count by the lymphocyte count, and the lymphocyte count by the monocyte count, respectively. Dichotomized analyses included neutrophil and lymphocyte counts and percentages, which were defined as the proportion of neutrophils or lymphocytes to all white blood cells in the sample. Values used for these calculations were part of the last complete blood count and differential obtained after neoadjuvant therapy and before operative intervention. Cutpoints of 5, 144.4, and 2.9 were used for NLR, PLR, and LMR, respectively. NLR cutpoints were determined on the basis of values used in previously published studies $[15,19]$. Cutpoints for PLR and LMR were not well established; therefore, the medians of the observed data were used.

Optimal NLR, PLR, and LMR cutpoints for the prediction of OS and RFS were determined using maximally selected rank statistics based on the log-rank method [20]. The resulting cutpoint for each ratio provided the best separation of the responses into 2 groups (in which the standardized rank statistics take their maximum). The $P$ value approximation was based on the improved 
Bonferroni inequality [21]. Variables were evaluated in relation to OS and RFS for predetermined cutpoints and newly identified best-fit cutpoints. All analyses were performed using $\mathrm{R}$ software (version 3.6.1).

\section{Results}

A total of 307 patients treated at our institution between 2007 and 2015 were eligible for this study. Two hundred seventy-seven patients with complete data met the inclusion criteria and were included in the analysis. The mean age was $68( \pm 10)$ years, $57 \%$ of whom were male. Twenty-five percent of patients had a Charlson Comorbidity Index $(\mathrm{CCI}) \leq 3,49 \%$ had a CCI of 4 to 5 , and $26 \%$ had a $\mathrm{CCI} \geq 6$. Medicare with a private supplement was the largest represented insurance provider among patients (42\%). Sixty-four percent of our cohort was classified as resectable and treated with upfront resection, and $37 \%$ received neoadjuvant systemic therapy. Margin negative (R0) resection was achieved in $90 \%$ of our patients, with 70 and $82 \%$ demonstrating lymphovascular and perineural invasion, respectively (Table 1 ).

Mean preoperative NLR, PLR and LMR was 3.4 \pm 2.2 , 169.1 \pm 95.7 , and $3.1 \pm 1.9$, respectively (Additional File $1)$. Using the predetermined cutpoints described above, $14 \%, 50 \%$, and $50 \%$ of patients demonstrated preoperative $N L R \geq 5, P L R \geq 144.4$, and $L M R \leq 2.9$, respectively. OS was significantly shorter among patients with an $\mathrm{NLR} \geq 5$ than patients with an NLR $<5$ in univariate (HR, 1.80 [95\% CI, 1.22-2.64]; $P=.003$ ) and multivariable (HR, 2.13 [95\% CI, 1.41-3.22]; $P=.002$ ) analyses (Table 2). Neither the PLR nor LMR demonstrated a significant association with OS (Table 2 and Fig. 1). Patients with a high NLR also demonstrated significantly worse RFS in univariate (HR, 1.65 [95\% CI, 1.14-2.39]; $P=.008$ ) and multivariable (HR, 2.20 [95\% CI, 1.433.39]; $P=0.0003$ ) analyses (Table 3 and Fig. 2). This was not observed with PLR or LMR. In multivariable analyses, pathologic $\mathrm{T}$ stage, presence of grade $3 / 4$ complications, $\mathrm{CCI} \geq 4$, NLR, node positivity, and perineural invasion were found to be significant predictors of OS and RFS (Tables 2 and 3).

Maximally selected rank analyses of NLR, PLR and LMR were performed to identify optimal cutpoints for predicting OS and RFS. OS optimal cutpoints for NLR, PLR, and LMR were 4.8, 192.6, and 1.7, respectively. For RFS, cutpoints were $4.9,120.4$, and 1.7 , respectively. Because neutrophil percentage is highly correlated with NLR we found the corresponding cutpoint for determining a high neutrophil percentage to be $78 \%$ (resulting in 38 patients being above the cutpoint). Similarly, lymphocyte percentage was highly negatively correlated, with NLR with a corresponding cutpoint percentage of $15 \%$. The components of NLR was analyzed separately to evaluate their prognostic importance. The lymphocyte percentage alone yielded a survival curve that was identical to that of the NLR, whereas the neutrophil percentage KM plot was not statistically significant (Additional File 2).

\section{Discussion}

We demonstrated a statistically significant association between preoperative NLR and both OS and RFS in PDAC patients who underwent curative-intent resection at a high-volume cancer center. PLR and LMR failed to demonstrate any correlation with survival. In addition, we identified optimal cutpoints for immunologic ratio survival analyses on the basis of our cohort data. Finally, we identified the lymphocyte component of NLR to be the primary driver of survival prognosis. To our knowledge, this is the largest US cohort utilized to analyze immunologic ratio biomarker-associated outcomes and perform dichotomized analyses for the purpose of identifying the prognostic driver of the NLR in surgical PDAC patients.

Inflammation and the inflammatory response have been discussed extensively in the literature in relation to tumorigenesis, progression, and metastasis. Furthermore, links have been established between the inflammatory response and oncogenic signaling pathway interactions, tumor microenvironment analyses, and use of immune-targeted therapies [22]. Surrogate biomarkers of inflammation have proven useful in predicting disease progression, recurrence, and overall prognosis across a wide range of malignancies $[10,11,23-25]$. In a meta-analysis evaluating the role of the systemic immune-inflammation index, Zhong et al. showed that an elevated systemic immune-inflammation index is associated with worse OS in hepatocellular carcinoma, urinary cancers, gastrointestinal cancers, and small-cell lung cancer [11]. In a review of 116 patients with gastrointestinal malignancies, Nora et al. demonstrated NLR and PLR to be significant predictors of lymph node positivity, metastatic disease, and recurrence, especially when used in combination [25]. The use of the NLR, PLR, and LMR have shown promise in pancreatic adenocarcinoma, demonstrating prognostic value in both resectable and palliative populations $[17,26]$.

The NLR has shown substantial potential for prognostic utility in pancreatic adenocarcinoma patients. In a large retrospective analysis of surgical PDAC patients, a low NLR $(<5)$ was associated with longer median survival ( 26 vs 13 months, $P=.001$ ), and an NLR $\geq 5$ independently predicted poor prognosis (HR, $1.66[95 \% \mathrm{CI}$ 1.12-2.46]; $P=.012$ ) [15]. Giakoustidis et al. further explored pretreatment NLR in surgical PDAC patients and identified decreased OS rates to be associated with a high NLR in univariate analyses, which maintained independent prognostic significance in multivariable analyses [13]. Two recent meta-analyses including a total of 9771 patients have also suggested an association between 
Table 1 Descriptive statistics of study cohorts

\begin{tabular}{|c|c|c|c|c|c|c|c|c|c|c|}
\hline Demographics & $\begin{array}{l}\text { Overall } \\
\boldsymbol{N}=277\end{array}$ & $\begin{array}{l}N L R<5 \\
\boldsymbol{N}=239\end{array}$ & $\begin{array}{l}N L R \geq 5 \\
\boldsymbol{N}=38\end{array}$ & $\begin{array}{l}P \\
\text { Value }\end{array}$ & $\begin{array}{l}\text { PLR }<144.4 \\
\boldsymbol{N}=139\end{array}$ & $\begin{array}{l}\text { PLR } \geq 144.4 \\
\boldsymbol{N}=138\end{array}$ & $\begin{array}{l}P \\
\text { Value }\end{array}$ & $\begin{array}{l}\mathrm{LMR} \leq 2.9 \\
\boldsymbol{N}=140\end{array}$ & $\begin{array}{l}\operatorname{LMR}>2.9 \\
\boldsymbol{N}=137\end{array}$ & $\begin{array}{l}P \\
\text { Value }\end{array}$ \\
\hline Age, median (range), y & $\begin{array}{l}68.0(33.0- \\
90.0)\end{array}$ & $\begin{array}{l}68.0(33.0- \\
90.0)\end{array}$ & $\begin{array}{l}67.5 \\
(47.0-86.0)\end{array}$ & .396 & $\begin{array}{l}69.0(40.0- \\
90.0)\end{array}$ & $\begin{array}{l}66.5(33.0- \\
86.0)\end{array}$ & .384 & $\begin{array}{l}68.0(33.0- \\
86)\end{array}$ & $\begin{array}{l}67.0(40.0- \\
90.0)\end{array}$ & .083 \\
\hline Sex, no. (\%) & & & & .715 & & & .103 & & & .239 \\
\hline Female & $120(43.3)$ & $102(42.7)$ & $18(47.4)$ & & $53(38.1)$ & $67(48.6)$ & & $66(47.1)$ & $54(39.4)$ & \\
\hline Male & $157(56.7)$ & $137(57.3)$ & $20(52.6)$ & & $86(61.9)$ & $71(51.4)$ & & $74(52.9)$ & $83(60.6)$ & \\
\hline Race, no. (\%) & & & & .166 & & & .279 & & & .383 \\
\hline Black & $11(3.97)$ & $11(4.60)$ & $0(0.00)$ & & $3(2.16)$ & $8(5.80)$ & & $4(2.86)$ & $7(5.11)$ & \\
\hline Other & $11(3.97)$ & $8(3.35 \%)$ & $3(7.89)$ & & $5(3.60)$ & $6(4.35)$ & & $4(2.86)$ & $7(5.11)$ & \\
\hline White & $255(92.1)$ & $\begin{array}{l}220 \\
(92.1 \%)\end{array}$ & $35(92.1)$ & & $131(94.2)$ & $124(89.9)$ & & $132(94.3)$ & $123(89.8)$ & \\
\hline BMI, median (range) & $\begin{array}{l}26.3 \\
(16.7-58.5)\end{array}$ & $\begin{array}{l}26.4 \\
(16.7-58.5)\end{array}$ & $\begin{array}{l}26.2 \\
(18.6-44.1)\end{array}$ & .841 & $\begin{array}{l}26.3 \\
(16.7-46.7)\end{array}$ & $\begin{array}{l}26.3 \\
(16.7-58.5)\end{array}$ & .976 & $\begin{array}{l}26.4 \\
(16.7-55.7)\end{array}$ & $\begin{array}{l}26.2 \\
(16.7-58.5)\end{array}$ & .848 \\
\hline CCl, no. (\%) & & & & .646 & & & .900 & & & .157 \\
\hline $0-3$ & $69(24.9)$ & $58(24.3)$ & $11(28.9)$ & & $33(23.7)$ & $36(26.1)$ & & $28(20.0)$ & $41(29.9)$ & \\
\hline $4-5$ & $136(49.1)$ & $120(50.2)$ & $16(42.1)$ & & 69 (49.6) & $67(48.6)$ & & $74(52.9)$ & $62(45.3)$ & \\
\hline$\geq 6$ & $72(26.0)$ & $61(25.5)$ & $11(28.9)$ & & $37(26.6)$ & $35(25.4)$ & & $38(27.1)$ & $34(24.8)$ & \\
\hline Tumor Size & $\begin{array}{l}2.70 \\
(0.08-8.20)\end{array}$ & $\begin{array}{l}2.70 \\
(0.08-8.20)\end{array}$ & $\begin{array}{l}2.70 \\
(0.60-6.50)\end{array}$ & .593 & $\begin{array}{l}3.00 \\
(0.10-8.20)\end{array}$ & $\begin{array}{l}2.5 \\
(0.08-7.00)\end{array}$ & .028 & $\begin{array}{l}2.60 \\
(0.08-7.00)\end{array}$ & $\begin{array}{l}2.90(0.10- \\
8.20)\end{array}$ & .123 \\
\hline Pathologic Stage, no. (\%) & & & & .439 & & & .126 & & & .642 \\
\hline T0 & $18(6.55)$ & $17(7.17)$ & $1(2.63 \%)$ & & $9(6.52)$ & $9(6.57)$ & & $11(7.91)$ & $7(5.15)$ & \\
\hline T1, no. (\%) & $23(8.36)$ & $18(7.59)$ & $5(13.2)$ & & $16(11.6)$ & $7(5.11)$ & & $10(7.19)$ & $13(9.56)$ & \\
\hline T2, no. (\%) & $132(48.0)$ & $116(48.9)$ & $16(42.1)$ & & $69(50.0)$ & $63(46.0)$ & & 69 (49.6) & $63(46.3)$ & \\
\hline T3 & $102(37.1)$ & $86(36.3)$ & $16(42.1)$ & & $44(31.9)$ & $58(42.3)$ & & $49(35.3)$ & $53(39.0)$ & \\
\hline $\begin{array}{l}\text { Preoperative Resectability, } \\
\text { no. (\%) }\end{array}$ & & & & .186 & & & .005 & & & $<.001$ \\
\hline Borderline & $101(36.5)$ & $83(34.7)$ & $18(47.4)$ & & $39(28.1)$ & $62(44.9)$ & & $68(48.6)$ & $33(24.1)$ & \\
\hline Resectable & $176(63.5)$ & $156(65.3)$ & $20(52.6)$ & & $100(71.9)$ & $76(55.1)$ & & $72(51.4)$ & $104(75.9)$ & \\
\hline $\begin{array}{l}\text { Neoadjuvant Therapy, no. } \\
\text { (\%) }\end{array}$ & & & & .204 & & & .008 & & & $<.001$ \\
\hline No & $175(63.2)$ & $155(64.9)$ & $20(52.6)$ & & $99(71.2)$ & $76(55.1)$ & & $71(50.7)$ & $104(75.9)$ & \\
\hline Yes & $102(36.8)$ & $84(35.1)$ & $18(47.4)$ & & $40(28.8)$ & $62(44.9)$ & & $69(49.3)$ & $33(24.1)$ & \\
\hline Margin, no. (\%) & & & & 1.00 & & & 1.00 & & & .145 \\
\hline Negative & $249(89.9)$ & $215(90.0)$ & $34(89.5)$ & & $125(89.9)$ & $124(89.9)$ & & $130(92.9)$ & $119(86.9)$ & \\
\hline Positive & $28(10.1)$ & $24(10.0)$ & $4(10.5)$ & & $14(10.1)$ & $14(10.1)$ & & $10(7.14)$ & $18(13.1)$ & \\
\hline $\begin{array}{l}\text { Lymphovascular Invasion, } \\
\text { no. (\%) }\end{array}$ & & & & 1.00 & & & .855 & & & .188 \\
\hline No & $83(30.5)$ & $72(30.5)$ & $11(30.6)$ & & $43(31.4)$ & $40(29.6)$ & & $47(34.6)$ & $36(26.5)$ & \\
\hline Yes & $189(69.5)$ & $164(69.5)$ & $25(69.4)$ & & $94(68.6)$ & $95(70.4)$ & & $89(65.4)$ & $100(73.5)$ & \\
\hline Perineural Invasion, no. (\%) & & & & .606 & & & .680 & & & .159 \\
\hline No & $50(18.4)$ & $45(19.1)$ & $5(13.9)$ & & $27(19.7)$ & $23(17.0)$ & & $30(22.1)$ & $20(14.7)$ & \\
\hline Yes & $222(81.6)$ & $191(80.9)$ & $31(86.1)$ & & $110(80.3)$ & $112(83.0)$ & & $106(77.9)$ & $116(85.3)$ & \\
\hline Complication 3-4a, no. (\%) & & & & .604 & & & .359 & & & 1.00 \\
\hline No & $241(87.0)$ & $209(87.4)$ & $32(84.2)$ & & $124(89.2)$ & $117(84.8)$ & & $122(87.1)$ & $119(86.9)$ & \\
\hline Yes & $36(13.0)$ & $30(12.6)$ & $6(15.8)$ & & $14(10.8)$ & $21(15.2)$ & & $18(12.9)$ & $18(13.1)$ & \\
\hline Completion of Adjuvant & & & & .155 & & & 1.00 & & & .166 \\
\hline
\end{tabular}


Table 1 Descriptive statistics of study cohorts (Continued)

\begin{tabular}{|c|c|c|c|c|c|c|c|c|c|c|}
\hline Demographics & $\begin{array}{l}\text { Overall } \\
\boldsymbol{N}=277\end{array}$ & $\begin{array}{l}N L R<5 \\
\boldsymbol{N}=239\end{array}$ & $\begin{array}{l}N L R \geq 5 \\
\boldsymbol{N}=38\end{array}$ & $\begin{array}{l}\boldsymbol{P} \\
\text { Value }\end{array}$ & $\begin{array}{l}\text { PLR }<144.4 \\
\boldsymbol{N}=139\end{array}$ & $\begin{array}{l}\text { PLR } \geq 144.4 \\
\boldsymbol{N}=138\end{array}$ & $\begin{array}{l}\boldsymbol{P} \\
\text { Value }\end{array}$ & $\begin{array}{l}L M R \leq 2.9 \\
\boldsymbol{N}=140\end{array}$ & $\begin{array}{l}\text { LMR }>2.9 \\
\boldsymbol{N}=137\end{array}$ & $\begin{array}{l}P \\
\text { Value }\end{array}$ \\
\hline No & $97(35.8)$ & 79 (33.9) & $18(47.4)$ & & 48 (35.6) & $49(36.0)$ & & $55(40.1)$ & $42(31.3)$ & \\
\hline Yes & $174(64.2)$ & $154(66.1)$ & $20(52.6)$ & & 87 (64.4) & $87(64.0)$ & & $82(59.9)$ & $92(68.7)$ & \\
\hline
\end{tabular}

${ }^{a}$ Clavien-Dindo Classification of Surgical Complications

Abbreviations: BMI body mass index, NLR neutrophil to lymphocyte ratio, $P L R$ platelet to lymphocyte ratio, $L M R$ lymphocyte to monocyte ratio, CCI Charleson Comorbidity Index

NLR and OS, in which elevated NLR carried poor prognoses. Zhou et al. found elevated NLR to be associated with shorter rates of OS (HR, 1.81 [95\% CI, 1.59-2.05]; $P<.00001)$ and disease-free survival $(\mathrm{HR}, 1.66[95 \% \mathrm{CI}$, 1.17-2.35]; $P=.005$ ) [27]. Evaluating OS alone, Mowbray et al. also demonstrated that significantly shorter rates of
OS were associated with elevated NLR (HR, 1.77 [95\% CI, 1.45-2.15]; $P<.01$ ) [28]. We corroborated these results in our own resected PDAC patients and similarly demonstrated that decreased rates of OS were associated with an NLR $\geq 5$ in multivariable analyses. Additionally, we showed a significant association between high

Table 2 Univariate and multivariate Cox proportional hazard models for overall survival

\begin{tabular}{|c|c|c|c|c|}
\hline Variable & $\begin{array}{l}\text { Univariate Analysis } \\
\text { HR }(95 \% \mathrm{Cl})\end{array}$ & $\boldsymbol{P}$ value & $\begin{array}{l}\text { Multivariable Analysis } \\
\text { HR }(95 \% \text { Cl) }\end{array}$ & $P$ value \\
\hline \multicolumn{5}{|l|}{ Gender } \\
\hline Female & N/A & N/A & 1.0 (Reference) & \\
\hline Male & N/A & N/A & $1.33(1.00-1.78)$ & .053 \\
\hline \multicolumn{5}{|l|}{ Age } \\
\hline$\leq 70$ & $\mathrm{~N} / \mathrm{A}$ & N/A & 1.0 (Reference) & \\
\hline$>70$ & N/A & N/A & $1.41(1.01-1.97)$ & .04 \\
\hline \multicolumn{5}{|l|}{ Pathologic Stage } \\
\hline T0 & N/A & N/A & 1.0 (Reference) & \\
\hline $\mathrm{T} 1$ & N/A & N/A & $1.36(0.53-3.54)$ & .53 \\
\hline $\mathrm{T} 2$ & N/A & N/A & $2.85(1.33-6.12)$ & .007 \\
\hline $\mathrm{T} 3$ & $\mathrm{~N} / \mathrm{A}$ & $\mathrm{N} / \mathrm{A}$ & $3.13(1.44-6.83)$ & .004 \\
\hline \multicolumn{5}{|l|}{$\mathrm{CCl}$} \\
\hline $0-3$ & $\mathrm{~N} / \mathrm{A}$ & N/A & 1.0 (Reference) & \\
\hline $4+$ & $\mathrm{N} / \mathrm{A}$ & N/A & $1.63(1.11-2.40)$ & .01 \\
\hline \multicolumn{5}{|l|}{ NLR } \\
\hline$<5$ & 1.0 (Reference) & & 1.0 (Reference) & \\
\hline$\geq 5$ & $1.80(1.22-2.64)$ & .003 & $2.13(1.41-3.22)$ & .002 \\
\hline \multicolumn{5}{|l|}{ PLR } \\
\hline$<144.4$ & 1.0 (Reference) & & N/A & N/A \\
\hline$\geq 144.4$ & $1.02(0.78-1.34)$ & .889 & N/A & N/A \\
\hline \multicolumn{5}{|l|}{ LMR } \\
\hline$<2.9$ & 1.0 (Reference) & & N/A & N/A \\
\hline$\geq 2.9$ & $0.82(0.63-1.08)$ & .156 & N/A & N/A \\
\hline \multicolumn{5}{|l|}{ Perineural Invasion } \\
\hline No & N/A & N/A & 1.0 (Reference) & \\
\hline Yes & N/A & N/A & $1.51(0.99-2.31)$ & .055 \\
\hline Complication Grade $(3-4)^{b}$ & $\mathrm{~N} / \mathrm{A}$ & $N / A$ & $2.37(1.57-3.57)$ & $<.0001$ \\
\hline Positive Nodes & N/A & $\mathrm{N} / \mathrm{A}$ & $1.07(1.03-1.12)$ & .002 \\
\hline
\end{tabular}

${ }^{a}$ model includes: age, gender, pathologic stage, $\mathrm{CCl}$, complication score, NLR, nodal and perineural invasion status. ${ }^{\mathrm{b}}$ Clavien-Dindo Classification of Surgical Complications

Abbreviations: CCI Charlson Comorbidity Score, NLR neutrophil to lymphocyte ratio, PLR platelet to lymphocyte ratio, $L M R$ lymphocyte to monocyte ratio 


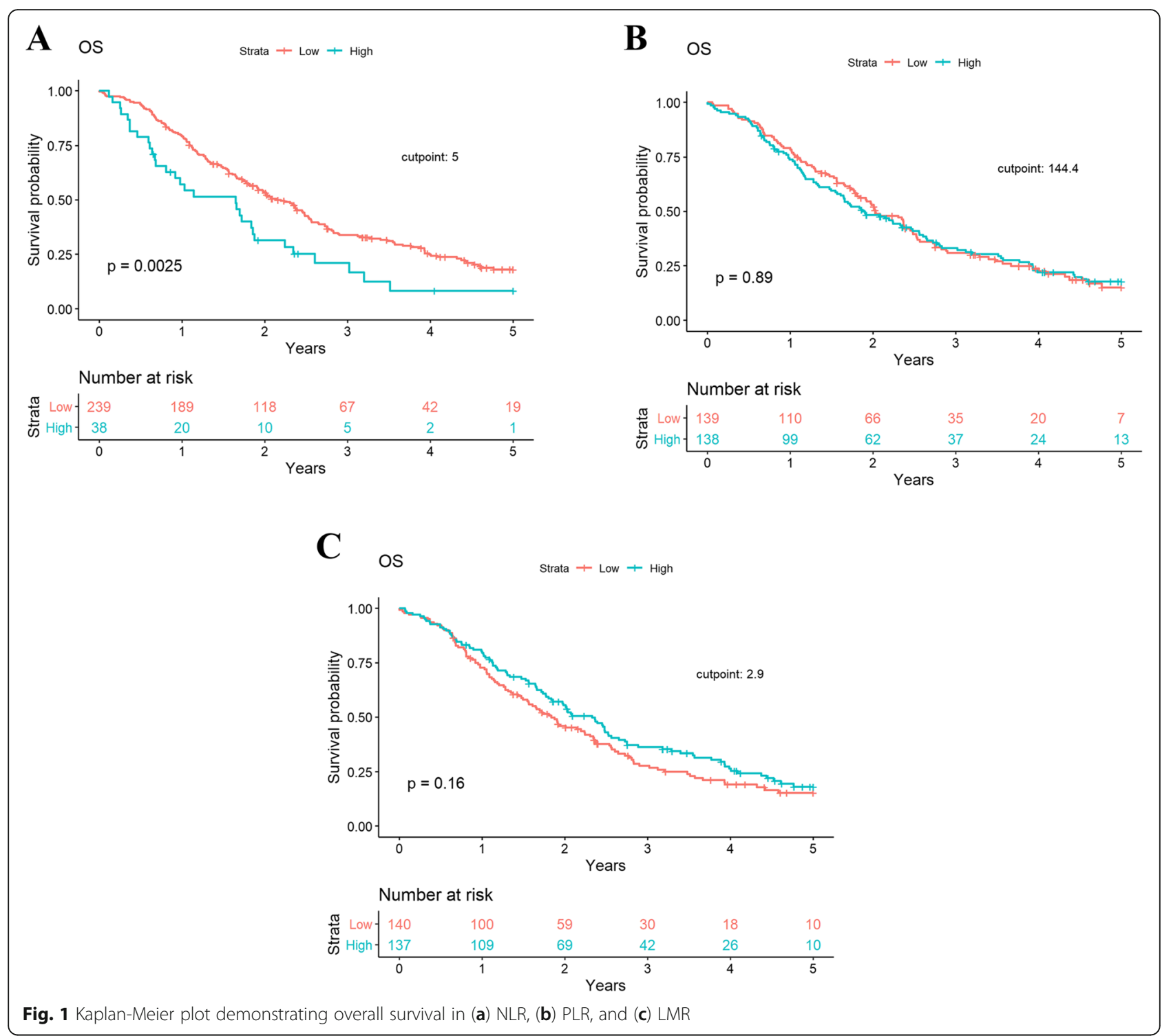

preoperative NLR and a decrease in RFS. Our study further supports the NLR as a valid prognostic biomarker for early-stage PDAC.

Although a cutpoint of 5 has been widely used to define high/low NLR, variations in cutpoints exists, with some groups using values ranging from 2 to 5 [15, 27$35]$. With no clearly defined cutpoint, we chose to perform a continuous analysis to identify an optimal cutpoint for the NLR in relation to survival. Based solely on the data from our cohort, optimal cutpoints of 4.8 for OS and 4.9 for RFS were obtained. Our study supports the prognostic value of the commonly used NLR cutpoint of 5 . As the NLR was the only significant ratio in our cohort, we elucidated its prognostic driver by analyzing the components of the ratio. The denominator, the lymphocyte count percentage, alone yielded a survival curve identical to the NLR, whereas the numerator, the isolated neutrophil count percentage, was not statistically significant, suggesting that lymphocyte count percentages have equal prognostic value and, perhaps, offer a simpler alternative to the NLR biomarker. This finding is supported by those from previous studies that showed low lymphocyte counts to be poor prognostic indicators in pancreatic and colorectal cancers [36-39]. The finding also has immunotherapeutic implications, which corroborate basic science findings on a population level [40-42].

In contrast to our study, other studies have found no prognostic significance of the NLR in some PDAC patient populations. Recently, Chawla et al. described a cohort of 217 resectable PDAC patients whose NLR at diagnosis did not correspond to OS [43]. Jamieson et al. similarly reported 135 patients who underwent PDAC resection and found no relationship between NLR and 
Table 3 Univariate and multivariate Cox proportional-hazard models for recurrence-free survival

\begin{tabular}{|c|c|c|c|c|}
\hline Variable & $\begin{array}{l}\text { Univariate Analysis } \\
\text { HR (95\% Cl) }\end{array}$ & $\boldsymbol{P}$ value & $\begin{array}{l}\text { Multivariable Analysis } \\
\text { HR }(95 \% \text { Cl) }\end{array}$ & $\boldsymbol{P}$ value \\
\hline \multicolumn{5}{|l|}{ Gender } \\
\hline Female & N/A & & 1.0 (Reference) & \\
\hline Male & $\mathrm{N} / \mathrm{A}$ & N/A & $1.25(0.95-1.65)$ & .11 \\
\hline \multicolumn{5}{|l|}{ Pathologic Stage } \\
\hline T0 & $\mathrm{N} / \mathrm{A}$ & & 1.0 (Reference) & \\
\hline $\mathrm{T} 1$ & $\mathrm{~N} / \mathrm{A}$ & $\mathrm{N} / \mathrm{A}$ & $1.29(0.55-3.00)$ & .56 \\
\hline $\mathrm{T} 2$ & $\mathrm{~N} / \mathrm{A}$ & N/A & $2.41(1.21-4.80)$ & .01 \\
\hline $\mathrm{T} 3$ & $\mathrm{~N} / \mathrm{A}$ & $\mathrm{N} / \mathrm{A}$ & $2.60(1.27-5.29)$ & .009 \\
\hline \multicolumn{5}{|l|}{$\mathrm{CCl}$} \\
\hline $0-3$ & N/A & & 1.0 (Reference) & \\
\hline $4+$ & $\mathrm{N} / \mathrm{A}$ & $\mathrm{N} / \mathrm{A}$ & $1.48(1.05-2.09)$ & .02 \\
\hline \multicolumn{5}{|l|}{ NLR } \\
\hline$<5$ & 1.0 (Reference) & & 1.0 (Reference) & \\
\hline$\geq 5$ & $1.65(1.14-2.39)$ & .008 & $2.20(1.43-3.39)$ & .0003 \\
\hline \multicolumn{5}{|l|}{ PLR } \\
\hline$<144.4$ & 1.0 (Reference) & & N/A & \\
\hline$\geq 144.4$ & $0.94(0.73-1.22)$ & .64 & N/A & N/A \\
\hline \multicolumn{5}{|l|}{ LMR } \\
\hline$<2.9$ & 1.0 (Reference) & & N/A & \\
\hline$\geq 2.9$ & $0.90(0.69-1.16)$ & .41 & N/A & N/A \\
\hline \multicolumn{5}{|l|}{ Perineural Invasion } \\
\hline No & N/A & & 1.0 (Reference) & \\
\hline Yes & N/A & N/A & $1.61(1.08-2.41)$ & .02 \\
\hline Complication Grade $(3-4)^{b}$ & N/A & N/A & $1.64(1.10-2.44)$ & .01 \\
\hline Positive Nodes & $\mathrm{N} / \mathrm{A}$ & N/A & $1.08(1.03-1.12)$ & .0003 \\
\hline
\end{tabular}

Abbreviations: CCI Charlson Comorbidity Score, NLR neutrophil to lymphocyte ratio, PLR platelet to lymphocyte ratio, $L M R$ lymphocyte to monocyte ratio

a model includes: age, gender, pathologic stage, $\mathrm{CCl}$, complication score, NLR, nodal and perineural invasion status

${ }^{\mathrm{b}}$ Clavien-Dindo Classification of Surgical Complications

survival [29]. Similar findings have been reported by other groups [30,31]. The reasons for this variability include diverse patient populations, differences in ratio cutpoints, timing of blood collections, and receipt of neoadjuvant therapy. In the current study, $37 \%$ of patients received neoadjuvant therapy before pancreatic resection, which may have influenced immune cell populations.

Increased monocyte presence in the tumor microenvironment or in circulation has been implicated in angiogenesis, tumor growth, and poor prognosis in cancer patients [44]. Circulating monocytes are commonly quantified by the LMR, which has demonstrated an inverse association with survival and prognosis in solid tumor malignancies [45]. Few studies have investigated this parameter in surgical PDAC patients. In a large review and meta-analysis of 1795 patients, $\mathrm{Li}$ et al. reported a favorable prognosis associated with elevated LMR in pooled analyses (HR, 0.56 [95\% CI, 0.38-0.83];
$P=.004)$ [16]. Although this study included a range of LMR cutpoints and both resected and nonoperable PDAC patients, a prognostic value of the LMR was observed in surgical patients in subgroup analyses [16]. Sierzega et al. reported a series of 442 resectable PDAC patients demonstrating prolonged median survival (29.2 vs 13.1 months, $P=.001$ ) in the LMR $\geq 3$ group [15]. An LMR $<3$ was an independent predictor of poor prognosis (HR, 1.65 [95\% CI, 1.06-2.58]; $P=.026$ ) [15]. In contrast to studies previously discussed, Abe et al. demonstrated no association between LMR and OS or disease-free survival in a large retrospective analysis of the prognostic effects of patient-specific nutritional and immunologic factors in resected PDAC patients [17]. We also did not show a prognostic value of LMR in our analyses of resected PDAC patients. Differences in prognostic outcomes were likely due to the paucity of data evaluating LMR and survival, inconsistency in evaluated patient cohorts, and variation of cutpoint delineation. 


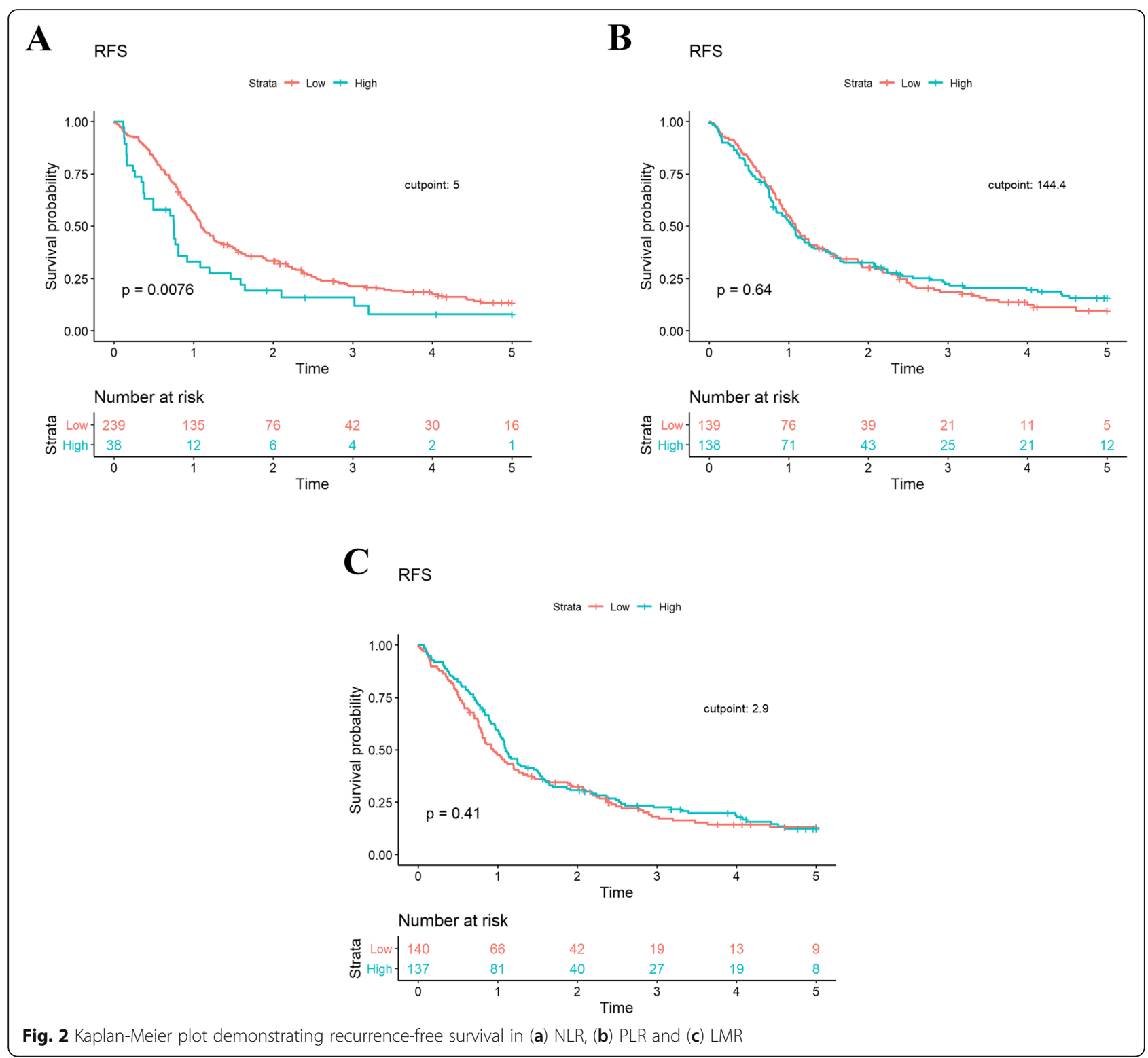

We used mean values for LMR cutpoints in our analyses because of the variation of cutpoints reported in the literature. An optimal cutpoint analysis of LMR for OS and RFS was performed to clarify the reporting of LMR associated outcomes.

Survival outcomes have similarly been linked to elevated PLR in solid tumor malignancies [46]. Compared to other commonly described ratios, the application of PLR to PDAC is less clear, with mixed outcomes reported. Giakoustidis et al. also investigated pretreatment PLR in surgical PDAC patients and identified decreased OS with high PLR in univariate analyses [13]. The PLR did not maintain independent prognostic significance in multivariable analysis. Interestingly, patients with concurrently high NLR and PLR experienced significantly decreased OS when compared to those with normal NLR and PLR or those with an elevation of either ratio (7, 48, 32\%, respectively; $P=.001$ ) [13]. In a subsequent analysis of resected and inoperable PDAC patients, Stotz et al. found no association between OS (HR, 1.13 [95\% CI: $0.82-1.57] ; P=.46)$ and PLR (HR, 1.07 [95\% CI, $0.82-1.40$ ]; $P=.61$ ) in either cohort [33]. Similarly, no demonstrable association between PLR and OS was observed in several separate resected PDAC patient series $[15,29,31,35]$. Consistent with the literature discussed above, our study did not find a significant correlation between survival (OS or RFS) and PLR in resected PDAC patients.

However, some authors have demonstrated the PLR to be an important predictor of survival. Smith et al. and 
Watanabe et al. reported elevated PLRs as the most significant determinant of survival in their resected PDAC cohorts of 110 and 46 patients, respectively [30, 47]. Reasons for inconsistent results may have included differing PLR cutpoint values, small patient cohorts, and variations in multidisciplinary treatments of these patients with complex PDAC. Furthermore, the PLR was synthesized using surrogates that are fundamental to many biologic functions (ie, coagulation cascade), which may explain the variability of correlation in oncologic outcomes. In our study, mean values were initially used for PLR cutpoints because of the variation reported in the literature. Again, an optimal PLR cutpoint analysis was performed to provide clarity and consistency in the reporting of PLR-associated factors.

The limitations of this study include those inherent in reviewing retrospective data. Although our data set was robust and associated with an electronic medical record, the potential for selection bias exists. Additionally, although all blood specimens were collected in the preoperative setting, there is potential for variation regarding the date and time blood draws were done in relation to the surgery date. The present study did not stratify patients based on receipt of neoadjuvant therapy. This stratification was previously investigated by our group, who reported significantly decreased rates of OS among patients with increased NLR after neoadjuvant therapy when compared to those with stable NLR [14]. Finally, we did not analyze pretreatment immunologic ratios in patients who received neoadjuvant chemotherapy; therefore, we were not able to determine whether chemotherapy significantly altered preoperative values.

\section{Conclusion}

There continues to be little doubt about the importance of inflammation and immunity in cancer biology. The NLR and other immunologic ratios are derived from easily obtainable standard laboratory values, with little added expense. When obtained in the preoperative setting, the NLR is a biomarker with the potential to guide treatment algorithms in early-stage PDAC patients and provide clarity on common unresolved management dilemmas routinely debated today. Given their demonstrable poor outcomes, patients with high NLR may benefit from neoadjuvant systemic therapy variation, more detailed preoperative staging, or stratification in clinical trials. Additionally, consistent with the findings of developing research on the tumor microenvironment and immunotherapy, lymphocytes alone may be significant drivers of survival. In the context of improving outcomes, our results suggest targeting inflammatory pathways may be relevant in chemoprevention. Prospective trials would serve to elucidate the provided prognostic information and provide insight into alternative treatment algorithms that can improve outcomes among patients with PDAC.

\section{Supplementary information}

Supplementary information accompanies this paper at https://doi.org/10. 1186/s12885-020-07182-9.

Additional file 1. Summary statistics of immunologic ratios.

Additional file 2. Kaplan-Meier plot demonstrating overall survival (OS) in dichotomized NLR values: (a) Neutrophil and lymphocyte (b) percentage.

\section{Abbreviations}

CCl: Charlson Comorbidity Index; LMR: Lymphocyte to monocyte ratio; NLR: Neutrophil to lymphocyte ratio; OS: Overall survival; PDAC: Pancreatic ductal adenocarcinoma; PLR: Platelet to lymphocyte ratio; RO: Margin negative resection; RFS: Recurrence-free survival

\section{Acknowledgments}

Editorial assistance was provided by the Moffitt Cancer Center's Scientific Editing Department by Dr. Paul Fletcher \& Daley Drucker. No compensation was given beyond their regular salaries. This work was presented as a poster at the 2019 AHPBA meeting and the 2019 Pancreas Club Meeting. The abstract of this work was previously published in HPB Journal.

\section{Authors' contributions}

DP: Conception and design, acquisition of data, analysis and interpretation of data, drafting of original article, critical revision. Gave final approval of completed manuscript. DR: Conception and design, acquisition of data analysis and interpretation of data, drafting of original article, critical revision. Gave final approval of completed manuscript. BP: Conception and design, acquisition of data, analysis and interpretation of data, critical revision. Gave final approval of completed manuscript. GM: Conception and design, acquisition of data, critical revision. Gave final approval of completed manuscript. SE: Conception and design, acquisition of data, critical revision. Gave final approval of completed manuscript. ZT: Statistical analysis and interpretation of data, critical revision. Gave final approval of completed manuscript. MS: Statistical analysis and interpretation of data, critical revision. Gave final approval of completed manuscript. PH: Conception and design, analysis and interpretation of data, critical revision. Gave final approval of completed manuscript. JP: Conception and design, analysis and interpretation of data, critical revision. Gave final approval of completed manuscript. JF: Conception and design, analysis and interpretation of data, critical revision. Gave final approval of completed manuscript. MM:

Conception and design, primary investigator supervision, analysis and interpretation of data, critical revision. Gave final approval of completed manuscript

\section{Funding}

This work was supported by the H. Lee Moffitt Cancer Center \& Research Institute NCl Cancer Center Support Grant (P30-CA076292). The funders had no role in study design, data collection and analysis, decision to publish, or preparation of the manuscript.

\section{Availability of data and materials}

The data that support the findings of this study are available from the corresponding author upon reasonable request.

\section{Ethics approval and consent to participate}

This study was approved by the Moffitt Cancer Center Institutional Review Board (MCC \#16446). Because of the retrospective nature of this study, patient consent was not required; no personally identifiable data for any patients were included. The study was performed in accordance with the Declaration of Helsinki.

\section{Consent for publication}

This study was approved by the Moffitt Cancer Center Institutional Review Board (MCC \#16446). Due to the retrospective nature of this study, patient consent was not required. 


\section{Competing interests}

The authors have no conflicts of interest to declare.

\section{Author details}

'Department of Gastrointestinal Oncology, H. Lee Moffitt Cancer Center and Research Institute, 12902 USF Magnolia Dr, Tampa, FL 33612, USA.

${ }^{2}$ Department of Surgery, University of Texas Southwestern, Dallas, TX, USA.

${ }^{3}$ Department of Biostatistics and Bioinformatics, H. Lee Moffitt Cancer Center and Research Institute, Tampa, FL, USA.

\section{Received: 27 April 2020 Accepted: 14 July 2020}

Published online: 11 August 2020

\section{References}

1. Siegel RL, Miller KD, Jemal A. Cancer statistics, 2019. CA Cancer J Clin. 2019; 69(1):7-34.

2. Ryan DP, Hong TS, Bardeesy N. Pancreatic adenocarcinoma. N Engl J Med. 2014;371(11):1039-49.

3. Katz $M H$, Wang $H$, Fleming JB, et al. Long-term survival after multidisciplinary management of resected pancreatic adenocarcinoma. Ann Surg Oncol. 2009;16(4):836-47.

4. Neoptolemos JP, Palmer DH, Ghaneh P, et al. Comparison of adjuvant gemcitabine and capecitabine with gemcitabine monotherapy in patients with resected pancreatic cancer (ESPAC-4): a multicentre, open-label, randomised, phase 3 trial. Lancet. 2017;389(10073):1011-24.

5. Oettle $H$, Neuhaus $P$, Hochhaus A, et al. Adjuvant chemotherapy with gemcitabine and long-term outcomes among patients with resected pancreatic cancer: the CONKO-001 randomized trial. Jama. 2013;310(14): 1473-81.

6. Chen DT, Davis-Yadley AH, Huang PY, et al. Prognostic fifteen-gene signature for early stage pancreatic ductal adenocarcinoma. PLoS One. 2015;10(8):e0133562.

7. Helm J, Centeno BA, Coppola D, et al. Histologic characteristics enhance predictive value of American joint committee on Cancer staging in resectable pancreas cancer. Cancer. 2009;115(18):4080-9.

8. Proctor MJ, Morrison DS, Talwar D, et al. A comparison of inflammationbased prognostic scores in patients with cancer. A Glasgow Inflammation Outcome Study. Eur J Cancer. 2011;47(17):2633-41.

9. Bindea G, Mlecnik B, Tosolini M, et al. Spatiotemporal dynamics of intratumoral immune cells reveal the immune landscape in human cancer. Immunity. 2013;39(4):782-95.

10. Hong X, Cui B, Wang M, Yang Z, Wang L, Xu Q. Systemic immuneinflammation index, based on platelet counts and neutrophil-lymphocyte ratio, is useful for predicting prognosis in small cell lung Cancer. Tohoku J Exp Med. 2015;236(4):297-304.

11. Zhong JH, Huang DH, Chen ZY. Prognostic role of systemic immuneinflammation index in solid tumors: a systematic review and meta-analysis. Oncotarget. 2017:8(43):75381-8.

12. Templeton AJ, McNamara MG, Seruga B, et al. Prognostic role of neutrophilto-lymphocyte ratio in solid tumors: a systematic review and meta-analysis. J Natl Cancer Inst. 2014;106(6):dju124.

13. Giakoustidis A, Neofytou K, Costa Neves M, et al. Identifying the role of neutrophil-to-lymphocyte ratio and platelets-to-lymphocyte ratio as prognostic markers in patients undergoing resection of pancreatic ductal adenocarcinoma. Ann Hepatobiliary Pancreatic Surg. 2018;22(3):197-207.

14. Glazer ES, Rashid OM, Pimiento JM, Hodul PJ, Malafa MP. Increased neutrophil-to-lymphocyte ratio after neoadjuvant therapy is associated with worse survival after resection of borderline resectable pancreatic ductal adenocarcinoma. Surgery. 2016;160(5):1288-93.

15. Sierzega M, Lenart M, Rutkowska M, et al. Preoperative neutrophillymphocyte and lymphocyte-monocyte ratios reflect immune cell population rearrangement in Resectable pancreatic Cancer. Ann Surg Oncol. 2017;24(3):808-15.

16. Li W, Tao L, Zhang L, Xiu D. Prognostic role of lymphocyte to monocyte ratio for patients with pancreatic cancer: a systematic review and metaanalysis. OncoTargets Ther. 2017;10:3391-7.

17. Abe T, Nakata K, Kibe S, et al. Prognostic value of preoperative nutritional and immunological factors in patients with pancreatic ductal adenocarcinoma. Ann Surg Oncol. 2018;25(13):3996-4003.

18. Quigley DA, Dang HX, Zhao SG, et al. Genomic hallmarks and structural variation in metastatic prostate Cancer. Cell. 2018;174(3):758-69 e759.
19. Halazun KJ, Aldoori A, Malik HZ, et al. Elevated preoperative neutrophil to lymphocyte ratio predicts survival following hepatic resection for colorectal liver metastases. Eur J Surg Oncol. 2008;34(1):55-60.

20. Lausen B, Schaumacher M. Maximally Selected Rank Statistics. Biometrics. 1992;48(1):73-85.

21. Lausen B, Sauerbrei W, Schumacher V. Classification and regression trees (CART) used for the exploration of prognostic factors measured on different scales. In: University of Essex Research Repository; 1994. p. 483-96.

22. Mantovani A, Allavena P, Sica A, Balkwill F. Cancer-related inflammation. Nature. 2008;454(7203):436-44.

23. Giakoustidis A, Neofytou K, Khan AZ, Mudan S. Neutrophil to lymphocyte ratio predicts pattern of recurrence in patients undergoing liver resection for colorectal liver metastasis and thus the overall survival. J Surg Oncol. 2015;111(4):445-50.

24. Li C, Wen TF, Yan LN, et al. Postoperative neutrophil-to-lymphocyte ratio plus platelet-to-lymphocyte ratio predicts the outcomes of hepatocellular carcinoma. J Surg Res. 2015;198(1):73-9.

25. Nora I, Shridhar R, Huston J, Meredith K. The accuracy of neutrophil to lymphocyte ratio and platelet to lymphocyte ratio as a marker for gastrointestinal malignancies. J Gastrointest Oncol. 2018;9(5):972-8.

26. Ye S, Bai L. Comparison and validation of the value of preoperative inflammation marker-based prognostic scores in resectable pancreatic ductal adenocarcinoma. Cancer Manag Res. 2018;10:3405-17.

27. Zhou Y, Wei Q, Fan J, Cheng S, Ding W, Hua Z. Prognostic role of the neutrophil-to-lymphocyte ratio in pancreatic cancer: A meta-analysis containing 8252 patients. Clin Chim Acta. 2018;479:181-9.

28. Mowbray NG, Griffith D, Hammoda M, Shingler G, Kambal A, Al-Sarireh B. A meta-analysis of the utility of the neutrophil-to-lymphocyte ratio in predicting survival after pancreatic cancer resection. HPB. 2018;20(5): 379-84.

29. Jamieson NB, Denley SM, Logue J, et al. A prospective comparison of the prognostic value of tumor- and patient-related factors in patients undergoing potentially curative surgery for pancreatic ductal adenocarcinoma. Ann Surg Oncol. 2011;18(8):2318-28.

30. Smith RA, Bosonnet $L$, Raraty $M$, et al. Preoperative platelet-lymphocyte ratio is an independent significant prognostic marker in resected pancreatic ductal adenocarcinoma. Am J Surg. 2009;197(4):466-72.

31. Sanjay $\mathrm{P}$, de Figueiredo RS, Leaver $\mathrm{H}$, et al. Preoperative serum C-reactive protein levels and post-operative lymph node ratio are important predictors of survival after pancreaticoduodenectomy for pancreatic ductal adenocarcinoma. JOP. 2012;13(2):199-204.

32. Garcea G, Ladwa N, Neal CP, Metcalfe MS, Dennison AR, Berry DP. Preoperative neutrophil-to-lymphocyte ratio (NLR) is associated with reduced disease-free survival following curative resection of pancreatic adenocarcinoma. World J Surg. 2011;35(4):868-72.

33. Stotz M, Gerger A, Eisner F, et al. Increased neutrophil-lymphocyte ratio is a poor prognostic factor in patients with primary operable and inoperable pancreatic cancer. Br J Cancer. 2013;109(2):416-21.

34. Hamed MO, Roberts KJ, Smith AM, Morris SG. Elevated pre-operative neutrophil to lymphocyte ratio predicts disease free survival following pancreatic resection for periampullary carcinomas. Pancreatology. 2013; 13(5):534-8.

35. Bhatti I, Peacock O, Lloyd G, Larvin M, Hall RI. Preoperative hematologic markers as independent predictors of prognosis in resected pancreatic ductal adenocarcinoma: neutrophil-lymphocyte versus platelet-lymphocyte ratio. Am J Surg. 2010;200(2):197-203.

36. Xiao Y, Xie Z, Shao Z, et al. Neutrophil and lymphocyte counts at diagnosis are associated with overall survival of pancreatic cancer: a retrospective cohort study. Medicine. 2016;95(40):e5024.

37. Rho SY, Hwang HK, Chong JU, Yoon DS, Lee WJ, Kang CM. Association of preoperative total lymphocyte count with prognosis in resected left-sided pancreatic cancer. ANZ J Surg. 2019;89(5):503-8.

38. Fogar P, Sperti C, Basso D, et al. Decreased total lymphocyte counts in pancreatic cancer: an index of adverse outcome. Pancreas. 2006;32(1):22-8.

39. Shinji S, Ueda Y, Yamada T, et al. Combined use of preoperative lymphocyte counts and the post/preoperative lymphocyte count ratio as a prognostic marker of recurrence after curative resection of stage II colon cancer. Oncotarget. 2018;9(2):2553-64.

40. Lohneis $P$, Sinn M, Bischoff $S$, et al. Cytotoxic tumour-infiltrating $T$ lymphocytes influence outcome in resected pancreatic ductal adenocarcinoma. Eur J Cancer. 2017:83:290-301. 
41. Karakhanova S, Ryschich E, Mosl B, et al. Prognostic and predictive value of immunological parameters for chemoradioimmunotherapy in patients with pancreatic adenocarcinoma. Br J Cancer. 2015;112(6):1027-36.

42. Shibuya KC, Goel VK, Xiong W, et al. Pancreatic ductal adenocarcinoma contains an effector and regulatory immune cell infiltrate that is altered by multimodal neoadjuvant treatment. PLoS One. 2014;9(5):e96565.

43. Chawla A, Huang TL, Ibrahim AM, Hardacre JM, Siegel C, Ammori JB. Pretherapy neutrophil to lymphocyte ratio and platelet to lymphocyte ratio do not predict survival in resectable pancreatic cancer. HPB. 2018;20(5):398-404.

44. Lee HW, Choi HJ, Ha SJ, Lee KT, Kwon YG. Recruitment of monocytes/ macrophages in different tumor microenvironments. Biochim Biophys Acta. 2013;1835(2):170-9.

45. Nishijima TF, Muss HB, Shachar SS, Tamura K, Takamatsu Y. Prognostic value of lymphocyte-to-monocyte ratio in patients with solid tumors: a systematic review and meta-analysis. Cancer Treat Rev. 2015:41(10):971-8.

46. Templeton AJ, Ace O, McNamara MG, et al. Prognostic role of platelet to lymphocyte ratio in solid tumors: a systematic review and meta-analysis. Cancer Epidemiol Biomarkers Prev. 2014;23(7):1204-12.

47. Watanabe J, Otani S, Sakamoto T, et al. Prognostic indicators based on inflammatory and nutritional factors after pancreaticoduodenectomy for pancreatic cancer. Surg Today. 2016;46(11):1258-67.

\section{Publisher's Note}

Springer Nature remains neutral with regard to jurisdictional claims in published maps and institutional affiliations.

Ready to submit your research? Choose BMC and benefit from:

- fast, convenient online submission

- thorough peer review by experienced researchers in your field

- rapid publication on acceptance

- support for research data, including large and complex data types

- gold Open Access which fosters wider collaboration and increased citations

- maximum visibility for your research: over $100 \mathrm{M}$ website views per year

At $\mathrm{BMC}$, research is always in progress.

Learn more biomedcentral.com/submissions 